\title{
AJARAN BHATARA SIWA DALAM LONTAR ANDHA BHUWANA KAJIAN PENDIDIKAN KARAKTER
}

\author{
Oleh \\ I Wayan Artayasa \\ Universitas Hindu Negeri I Gusti Bagus Sugriwa Denpasar \\ yanarta84@,gmail.com
}

\begin{abstract}
Bhatara Shiva's teachings comprise various moral, ethical, and susila values. This value is exceptionally well practised and implemented in daily life. This value is included in Balinese Hindu religious texts, notably lontar texts. From ancient times to the present, the existence of lontar manuscripts to be studied and researched proceeds to expand to reveal character education values. One of the teachings of Hinduism is conveyed through stories. Character education is conveyed so that humankind is presented descriptions of knowledge, between good and bad; thus, they can choose one of those options. Both good and bad deeds have their respective consequences, which of course all religions expect that humans frequently do good things. Lontar Andha Bhuwana carries out stories regarding the teachings of Bhatara Shiva which need to be observed because they contain conversations between parents as a father (Bhatara Siwa), as a mother (Bhatara Giri Putri), and as a child (Bhatara Gana / Ganesha). This story is highly relevant as a reflection of education, primarily character education and has meaning in forming household harmony. Obligations as children devoted to their parents, be grateful for life, self-purification (pangruatan), and harmonise nature.
\end{abstract}

Keywords: Lord Shiva's Teachings, Andha Bhuwana, Character Education.

\section{PENDAHULUAN}

Ajaran Bhatara Siwa yang termuat dalam naskah lontar sangat diyakini oleh masyarakat Hindu Bali dan dijadikan pedoman dalam kehidupannya sehari-hari. Masyarakat Hindu Bali percaya 101endidikan yang diwariskan oleh leluhurnya sehingga keberadaan naskah-naskah lontar masih terawatt dan terjaga sehingga dapat dipelajari dan diteliti lebih lanjut. Ajaran-ajaran Bhatara Siwa sangat relevan utuk mencegah adanya degradasi moral, etika yang kurang baik, tawuran, miras, narkoba dan kegiatan terlarang lainnya. Ajaran yang adiluhung sangat baik diterapkan dan dilaksanakan, apalagi termuat dalam teks-teks keagamaan khususnya lontar. Ajaran agama Hindu tidak lekang oleh waktu selalu eksis dalam perkembangan zaman dan terus berkembang sesuai dengan Desa (tempat), Kala (waktu) Patra (sastra/kitab di sebuah tempat).

Pendidikan Karakter sangat diperlukan oleh umat manusia, baik itu orang tua, maupun anak. Di dalam ajaran Agama Hindu salah satunya disampaikan melalui cerita-cerita atau tutur-tutur, percakapanpercakapan antara Dewa yang satu dengan Dewa yang lainnya dan disimbulkan sebagai orang tua dan anak. Pendidikan karakter tersebut disampaikan agar umat manusia diberikan gambaran-gambaran pengetahuan, antara kebaikan dengan ketidakbaikan, nantinya manusia memilih mana yang baik

Ajaran Bhatara Siwa dalam Lontar Andha Bhuwana Kajian Pendidikan Karakter Universitas Hindu Negeri I Gusti Bagus Sugriwa Denpasar 
mana yang buruk. Kedua perbuatan baik dan buruk membawa konsekuensi masingmasing, yang tentunya semua Agama mengharapkan agar manusia selalu berbuat kebaikan.

Pendidikan Karakter dalam Agama Hindu di Bali disampaikan dalam bentuk cerita-cerita yang banyak tertuang dalam lontar-lontar. Pendidikan Karakter dalam lontar Andha Bhuwana di sampaikan oleh Bhatara Siwa kepada anak dan kepada istrinya. Anak, istri dalam konsep Dewa-dewa dalam Ajaran Agama Hindu hanya sebagai simbul saja, dimana tujuannya agar mudah dipahami oleh umat manusia dan tujuannya agar lebih 102endidi dimasyarakat. Disamping itu juga cerita masih sangat digemari oleh kalangan anak-anak, remaja, maupun dewasa. Cerita-cerita tersebut sudah dipercayai secara turun-temurun disegala aspek keberagamaan masyarakat Hindu Bali. Dengan adanya cerita tersebut sangat diperlukan oleh Bangsa Indonesia untuk membangun Karakter Bangsa.

Lontar-lontar atau sumber referensi Agama Hindu di Bali masih tersimpan di masyarakat maupun di Pusat Dokumentasi Provinsi Bali, di Gedong Kertia Singaraja maupun ditempat-tempat penting lainnya, dalam hal ini peneliti terus menelusuri lontarlontar maupun referensi lainnya dalam hubungannya dengan Pendidikan Karakter yang nantinya bisa berguna bagi anak, bahkan sampai orang tua. Perkembangan atau kemajuan teknologi ajaran-ajaran Agama sangat diperlukan untuk menangkal hal-hal yang bersifat 102endidik, apalagi generasi muda banyak yang masih labil. Perkembangan teknologi harus disikapi 102endidi baik orang tua, masyarakat maupun pemerintah, orang tua sangat berperan dalam menanamkan 102endidikan karakter karena anak-anak lebih banyak 102endidi orang tua di rumah dibandingkan di sekolah, masa-masa sekolah, masa-masa muda sangat menentukan kualitas hidup seseorang, 102endi orang tua perhatian terhadap anaknya niscaya anaknya akan tunduk hormat kepada orang tua, begitu sebaliknya.

Lontar Andha Bhuwana yang memuat tentang ajaran Bhatara Siwa perlu dicermati karena berisi percakapan orang tua sebagai ayah (Bhatara Siwa), sebagai ibu (Bhatara Giri Putri), dan sebagai anak (Bhatara Gana/Ganesa), cerita ini sangat relevan sebagai cerminan dalam mendidik 102endidikan karakter. Diceritakan pada waktu pertemuan beliau Sang Hyang Paramestiguru (Sang Hyang Siwa) dengan Bhatari Giriputri pada waktu ngidam, beliau mengidamkan air susu lembu yang selalu menjadi keinginannya untuk diminum. Kemudian Bhatara Siwa menyuruh Bhatari Giriputri berangkat mendatangi desa-desa, hutan, dan juga pertapaan yang ada di gunung. Tujuannya adalah menemukan orang yang memelihara lembu, dan berusaha mendapatkan air susu lembu pada sang pengembala lembu dengan cara membeli dengan emas, perak, uang dan intan. Perjalanan Bhatari Giriputri mencari susu lembu mendapatkan hasil, tetapi dengan melanggar perintah Bhatara Siwa. Bhatari Giri Putri mendapatkan air susu lembu dengan jalan bersenggama dengan pemilik lembu. Kemudian Bhatara Gana mengetahui prilaku ibunya tersebut sehingga Bhatari Giriputri mendapat kutukan. Oleh karena itulah perlu diungkapkan lebih lanjut tentang adanya ajaran Bhatar Siwa dalam Lontar Andha Bhuwana Kajian pendidikan Karakter.

\section{PEMBAHASAN}

\section{Karakter jujur}

Jujur merupakan hal yang paling utama harus ditanamkan pada setiap anak didik. Jujur memiliki pengertian lurus hati, tidak curang (KBBI, 2009: 394). Karakter 
jujur adalah karakter yang tidak suka berbohong, berbuat curang, berkata apa adanya dan mengakui kesalahan, rela berkorban untuk kebenaran. Hal ini dapat dilihat pada kutipan berikut.

....,nihan atur Hyang Bhatari ring sira Hyang Paramestiguru, "uduh ta sira Hyang Bhatara Siwa, iki rengwakena ujar hulun atur akena ri sira de Bhatara, apang ta sira wruh ring cittan hulun. Hulun angrempini tan waneh cittan inghulun.

Terjemahan:

....,Inilah kata beliau Bhatari Giriputri kepada Bhatara Siwa; Ya Bhatara Siwa, dengarah ini permintaan hambamu kepada tuanku, supaya tuanku mengetahui pada keinginan hamba.

Sumahur Hyang Bhatari Giriputri, tur awor tangis, eling ring lampahe nguni: "Singgih sira Hyang Bhatara, ri mangka yukti ling Bhatara, wruh tang hulun ri laku nira sadokala, aksamakena tang hulun, Hyang Bhatara. Apan mamancut de Bhatara Paramasunya, mangke kadyangapa hyun de Bhatara?" sumahur Hyang Bhatara Gurureka: "Eh, Nini Dewati, yan mangkana ling ta, becik tumurun wenten ing mrecapada, moga ta sira siniwi dening rat kabeh". (Andha Bhuwana 9a)

Terjemahan:

Menjawablah Bhatari Giriputri, disertai dengan tangis meneteskan air mata, sebab teringat dengan perbuatannya lalu; "Ya hampun Bhatara, kalau demikian sangat patut sabda Bhatara, sebab hamba sudah sadar dengan perilaku hamba salah, ampunilah perbuatan hamba ya Bhatara, sebab hamba mengotori diri Bhatara, dan kini apakah kehendak paduka terhadap diri hamba?". Bersabdalah Bhatara Siwa; "Duhai Nini Hyang Bhatari, kalu demikian permintaan Bhatari, lebih baik Bhatari turun menetap di dunia, semogalah Bhatari dipuja oleh seluruh isi dunia.
Berdasarkan kutipan di atas menunjukkan bahwa awal cerita dalam naskah Andha Bhuwana sudah diceritakan kejujuran keinginan dari Bhatari Giriputri Untuk meminta air susu lembu. Dalam perjalanan berikutnya karena apa yang di idamkan tersebut susah di dapatkan, maka akhirnya Bhatari Giriputri berkata bohong menyembunyikan sesungguhnya apa yang di dapat dari pengembala lembu bukan membeli atau menukar dengan uang, emas dan permata air susu tersebut. Pada akhirnya mengakui kesalahan dan memhohon maaf kepada Bhatara Siwa.

\section{Karakter Religius}

Religius berkaitan dengan keagamaan, dalam hal ini karakter religius juga ditanamkan kepada masyarakat melalui upacara dan penebusan dosa yang dilakukan untuk mendapatkan kesucian. Hal ini dapat dilihat pada kutipan berikut.

Nging hana manusa minta agung laluputan, sasampurrayan maruntutan widhi widhana muwah segeh agung. Nghing sira dewati sampurakena dewa manusa kabeh.

Terjemahan

Akan tetapi bila ada manusia yang memohon ampun, disertai upacara dan segeh agung hendaknya dinda dewi mengampuni baik pada para dewa maupun manusia.

Berdasarkan kutipan di atas menerangkan bahwa upacara yang berkaitan dengan penebusan dosa yang dilakukan oleh manusia supaya diberikan pengampunan dan upacara persembahannya sesuai dengan upakara yang dilaksanakan.

\section{Karakter Tanggung Jawab}

Karakter tanggung jawab adalah sikap dan perilaku seseorang untuk melaksanakan tugas dan kewajibannya. Baik pada diri sendiri maupun orang lain, menurut Miarta (2014: 37) menytakan tanggung jawab adalah sikap dan perilaku yang berani menanggung 
segala akibat dari perbuatan atau tindakan yang telah dilakukan. Hal ini dapat dilihat pada kutipan berikut.

...., "Uduh anak ira bapa, Si Gana, iki rengwakenajar hulun lawan kita anaku, agya ri lampah ira ibun ta Hyang Giriputri, duke lungha angulati we susu lembu, nda tan hana manusa adrewe lembu ring manusapada.

Terjemahan:

...., "Ya anakku Bhatara Gana, hendaknya didengarkan sabda ayahndamu ini, ya anakku, jemputlah kedatangan ibumu Bhatari Giriputri, dating dari mencari air susu lembu, tetapi tidak ada manusia yang mempunyai lembu di dunia.

Berdasarkan kutipan di atas menunjukkan bahwa Bhatara Siwa merasa bertanggung jawab atas keinginan dari Bhatari Giriputri mendapatkan air susu lembu di dunia. Karena mengetahui bahwa tidak ada yang mengembala lembu maka Bhatara Siwa menjelma menjadi pengangon lembu supaya Bhatari Giriputri mendapatkan air susu lembu yang di idamkannya. Namun dalam hal ini akhirnya menjadi pembelajaran untuk menguji kesetiaan dan kejujuran Bhatari Giriputri. Akhirnya Bhatara Gana menguji dan menanyakan bagaimana Bhatari Giriputri mendapatkan air susu lembu tersebut. Karakter tanggung jawab yang ditekankan dalam hal ini adalah berani berbuat tidak baik maka hasilnya harus dipertanggung jawabkan sendiri.

\section{Karakter bersahabat/komunikatif}

Karakter bersahabat atau komunikatif merupakan tindakan yang menunjukkan bahwa seseorang harus senang bergaul, berbicara dan bersahabat dengan yang lainnya. Dengan adanya komunikasi yang baik maka akan berdampak pada hal-hal yang baik. Hal ini dapat dilihat pada kutipan berikut.

Nihan rengakena ujar kami lawan anaku, tan len anaku ri mangke, anaku antanya lawan ibunta, yan tuhu, yan tan tuhu ri ulah pasanggama lawan kami. Tan len anaku ngitungi juga ibunta caritakena pawarah bapanta, kewala carita ring tenung wariga temen, mangkana uncarakena, aywa carita saking pawarah tang hulun.

Terjemahan:

Sekarang dengarkanlah sabda ayahmu ya anakku, tiada lain sekarang anakku bertanya kepada ibumu, apakah benar, atau berbohong tentang perbuatannya bersenggama dengan ayahmu, tidak lain anakku sekarang menguji ibumu, ceritakanlah sabda ayahandamu ini, tetapi ceritakan menurut kitab wariga tenung, itu hendaknya dibacakan, jangan kau ceritakan bahwa itu dari sabda ayahandamu.

Berdasarkan kutipan di atas digambarkan adanya komunikasi yang baik antara Bhatara Siwa dengan Bhatara Gana maka Bhatari Giriputri pada akhirnya mengakui semua perbuatan salah yang dilakukan. Secara komunikatif dan tidak langsung menuduh pada akhirnya kebohongan yang dilakukan akhirnya diakui. Walaupun pada akhirnya Bhatari Giriputri mendapatkan kutukan dari Bhatara Gana akibat membakar tenung wariga tetapi hubungan baik antara keluarga tetap terjaga. Sebagai seorang anak harus taat dan berbakti kepada orang tua dan orang tua harus menjadi contoh yang baik untuk anak-anaknya.

\section{Karakter Peduli Sosial}

Karakter peduli sosial merupakan sikap dan tindakan yang selalu memberikan kepada orang lain atau masyarakat yang membutuhkan. Dalam hal ini anak didik harus diberikan atau diajarkan peduli terhadap lingkungan dan sosial dimanapun berada.dalam cerita Andha Bhuwana dikisahkan kepedulian sosial berkaiatan dengan memberikan kepada orang lain sesuatu yang diinginkan dengan cara yang 
baik. Hal ini dapat dilihat pada kutipan berikut.

Saksana kadulu de Bhatàrì Girìputri, garjita hyun ira Bhatàrì, sigra ataña ring wwang angangon lêmbu, "Ih kita pangangon lêmbu, yan kita tuhu tumulus asih lawan minara, kaki hana pamidi nira kaki, manira arêpa atuku olih mas, pirak, rajata, wintên sakêpêl, kadyang apa kaki ?". Mangkana ling Bhatàrì.

Terjemahan:

Segera dilihat oleh Bhatari Giriputri, sangat gembira perasaannya, segera bertanya kepada pengembala lembu. Hai pengembala lembu, akalu benar-benar ikhlas kasihan denganku, ada permintanku padamu, aku berkeinginan membeli air susu lembumu dengan emas, perak, permata, intan segenggam, bagaimana pengembala lembu? Demikianlah sabda Bhatari Giriputri.

Berdasarkan kutipan di atas, seperti halnya ketika Bhatari Giriputri berkeinginan mendapatkan air susu lembu beliau harus membeli dengan uang, emas dan permata. Hal itu sudah dilakukan dan ditawarkan kepada pengembala lembu.Tetapi akhirnya karena sangat menginginkan air susu tersebut menuruti keinginan pengembala lembu supaya bersenggama. Kepedulian sosial yang seharusnya diterapkan adalah ketika seseorang membutuhkan sesuatu seharusnya diberikan secara ikhlas. Lebih-lebih pada saat orang sedang ngidam, seharusnya apa yang kita miliki berikan secara ikhlas dan tanpa pamrih untuk diberikan, bukan sesuatu yang memaksa dan merugikan orang lain.

\section{Karakter Menghargai Prestasi}

Karakter menghargai prestasi adalah sikap meghargai prestasi yang ditunjukkan dengan menghormati keberhasilan orang. Prestasi yang di dapat bisa berupa pujian atau hadiah. Dalam cerita Andha Bhuwana diceritakan bahwa Bhatara Gana Berhasil menyalin kembali wariga tenung yang dibakar oleh Bhatari Giriputri. Hal ini dapat dilihat pada kutipan berikut.

Ri wus mangkana, sigra Hyang Bhatàra Gana manurat manurun Hyang Aji Saraswati, mandadi waluya malih linggaksara dibya. Awune ika katurun de Bhatàra Gana, saksana waluya jati malingga aksara kadi lagi.

Terjemahan:

Setelah demikian, dengan sigapnya Bhatara Gana menulis kembali Sanghyang Aji Saraswati, menjadi sediakala lagi berwujud aksara utama. Abunya itu disalin oleh Bhatara Gana, seketika kembali lagi seperti wujudnya aksara seperti sediakala.

Berdasarkan kutipan di atas, dengan kesaktian dan pengetahuan yang dimiliki Bhatara Gana, ia menyalin kembali tenung wariga yang di bakar. Keberhasilannya itu sebagai sebuah bentuk prestasi yang pada nantinya akan menjadi tuntunan bagi masyarakat dalam melaksanakan kehidupan. Prestasi sebagai sebuah usaha yang berhasil ditunjukkan Bhatara Gana ketika mampu menunjukkan kebenaran dari perbuatan Bhatari Giriputri yang mendapat air susu lembu dengan cara yang tidak benar. Selain itu kutukan yang diberikan kepada Bhatari Giriputri dapat menjadikan kehidupan di dunia menjadi lebih baik, hal ini berarti bahwa setiap manusia yang berbuat tidak baik maka mendapatkan karma yang sesuai.

\section{Karakter Kerja Keras}

Karakter kerja keras adalah bersikap tidak mudah menyerah dan sungguh-sungguh melakukan sesuatu. Karakter kerja keras ditujukkan oleh semua tokoh dalam cerita Andha Bhuwana. Hal ini dapat dilihat dalam cerita yang menggambarkan bahwa tokoh pengembala lembu adalah sosok yang memiliki keinginan keras mendapatkan apa 
yang diingikan dengan tidak mudah tergoda materi. Apalagi selama ini pengembala lembu telah bekerja keras memberikan makan dan memelihara lembunya dengan baik. Hal ini dapat dilihat pada kutipan berikut.

Dadi sumahur I pangangon lembu: singgih ta sira bhatari, yen sira makon atuku we susuning lembu, hulun nora angadol we susu lembu olih mas pirak rajata winten. Mangkana atur I pangangon lembu.

Terjemahan:

Berkata sang pengembala lembu: Mohon hampun ya paduka Bhatàrì, kalau paduka ingin membeli air susunya lembu hamba, hamba tidak menjual air susu lembu hamba dengan emas, perak, permata maupun intan". Demikian katanya si pengembala lembu".

Eh ta sira kaki, apan kaki pangangon lembu, masasira manusa, apan kaparikedeh karep ta, nghing hulun pasung lawan ta, iki watek sukun hulun jamah ta.

Terjemahan:

Ya engkau pengembala, sebab engkau sebagai pengembala lembu, berupa manusia, sebab sangat teguh pendiriamu, nah sekarang aku memberikan padamu pada bagian kakiku engkau boleh menjamahnya".

Berdasarkan kutipan di atas, penegmbala lembu yang merupakan perwujudan Bhatara Siwa sudah bekerja merawat dengan baik lembu yang digembalakan. Bahkan tidak dengan mudah diberikan begitu saja susu lembu yang dimiliki. Bhatara Siwa dalam menjaga keseimbangan dunia juga berusaha keras dengan merubah wujud beliau menjadi orang lain supaya tetap menjaga keseimbangan dunia. Bhatara Gana sebagai anak juga berusaha keras melaksanakan perintah yang diberikan ayahnya dan mengungkapakan semua kebenaran.

Beberapa hal yang berkaitan dalam pendidikan karakter yang terdapat dalam cerita Andha Bhuwana seperti karakter jujur, religius, tanggung jawab, bersahabat/komunikatif, peduli sosial, menghargai prestasi, dan kerja keras memberikan ajaran kepada setiap orang terutama dalam hal pendidikan dapat mendidik anak menjadi memiliki kualitas dan kompetensi yang berani bersaing dalam segala bidang.

\section{Makna Ajaran Bhatara Siwa dalam Lontar Andha Bhuwana Kaitannya dengan Pendidikan Karakter}

Karakter dalam Agama Hindu identik dengan Budhi Pekerti yaitu sebagai ilmu yang mempelajari tata nilai, tentang baik dan buruknya suatu perbuatan apa yang harus dikerjakan atau dihindari, sehingga tercipta hubungan yang baik diantara sesama manusia. Salah satu aspek dalam ilmu Budi Pekerti adalah membahas aspek moral dan arti dari apa yang dikatakan baik dan tidak baik. Budi Pekerti adalah rasa cinta, rasa kasih sayang dimana seseorang yang menerima Budi Pekerti itu adalah karena ia mencintai dirinya sendiri dan menghargai orang lain.

Jadi dalam Agama Hindu Budi Pekerti dinamakan tata susila yang artinya sebagai peraturan tingkah laku baik dan mulia yang harus dijadikan pedoman hidup oleh manusia. Tujuannya adalah untuk memelihara hubungan baik yang selaras dan serasi diantara sesama manusia, sehingga tercapailah kehidupan masyarakat yang aman dan sentosa. Tata susila membina watak manusia untuk bisa menjadi anggota keluarga dan anggota masyarakat yang baik, menjadi putra Bangsa yang berpribadi mulia (Suhardana, 2006:20). 


\subsubsection{Makna Keharmonisan Perkawinan/Rumah Tangga}

Isi dari lontar Andha Bhuwana dalam bentuk cerita hubungan keluarga (rumah tangga) yaitu diwujudkan dalam Bhatara Siwa (suami), Bhatari Giriputri (istri) begitu juga sebagai anak yaitu Bhatara Gana sebagai anak dan sekaligus sebagai murid yang diberikan pengetahuan oleh ayah atau gurunya yaitu oleh Bhatara Siwa. Pentingnya menjaga keharmonisan dalam perkawinan dapat dijelaskan dalam kutipan berikut.

Dadi matur ta sira Sang Hyang Darmasiddhi ring sira Sang Hyang Tattwajñàna, makadi Sang Hyang Mengêt: "Uduh ta sira Hyang karwa, kadyang apa sangkan ing wwang gêring kacacar? Bhatàra wistarakêna juga apang wruh ring mànusapada, ri nimitanira wwang nampo gêring kacacar". Mangkana pajar ta Sang Hyang Darmasiddhi.

Sumahur ta sira Sang Hyang Tattwajñàna : "Singgih ta Sang Hyang, apa ta sira wruh Sang Hyang wruh ring mulaning wwang agêring kacacar, duh iki kami, aywa lupa, aywa tan sapada, duk patemun ira Hyang Bhatàra Paramesti guru ring Hyang Bhatàrì Girìputri angåmpini, tan len citta nira Bhatàrì, we susu andaka juga karêp ta".

Berdasarkan kutipan di atas, Lontar Andha Bhuwana menjelaskan bagaimana asal mulanya manusia menderita sakit cacar. Tujuannya supaya diketahui di seluruh dunia, tentang sebab musababnya orang menderita sakit cacar". Demikianlah pertanyaan sang hyang dharmasiddhi. Menjawablah beliau sang hyang tattwajñàna; ", jangan dilupakan, jangan tidak waspada. Pada waktu pertemuan beliau Sang Hyang Paramestiguru (Sang Hyang Śiwa) dengan Bhatàrì Girìnutri ngidam, tiada lain yang terngiang dalam pikiran beliau hanyalah air susu lêmbu yang selalu menjadi keinginannya".
Berkatalah beliau Bhatàrì Girìutri kepada Bhatàra Siwa. Inilah kata beliau Bhatàrì Girìnutri kepada Bhatàra Siwa ; "Ya tuanku Bhatàra Siwa, dengarlah ini permintaan hambamu kepada tuanku, supaya tuanku mengetahui pada keinginan hamba, ya tuanku, hamba sedang ngidam, tiada lain keinginan hamba, sebentar-sebentar timbul, sebentar-sebentar hilang, ya tuanku, ingin sekali hamba minum air susu lêmbu, bagaimana pendapat tuanku ?" demikianlah permohonan Bhatàrì Girìputri.

Menjawab beliau Sang Hyang Siwa : "Duhai Hyang Giriputri, kalau demikian permintaan andinda, tidak terkabul permintaan-Mu dindaku. Kalau menurut pendapatkanku, sebaiknya dindaku berangkat mendatangi desa-desa, dan hutan, juga di pertapaan yang ada di gunung, guna menemukan orang yang memelihara lembu, usahakanlah mendaptkan air susu pada sang pengembala lembu dengan jalan membeli dengan emas, perak, uang dan intan, lebih baik tanda dinda membelinya, jangan meminta". Demikianlah sabda Hyang Siwa.

Dari percakapan yang disajikan dalam cerita, pentingnya seorang suami istri terbuka dalam menginginkan sesuatu, hubungan yang harmonis antar keluarga akan memberikan dampak yang baik dalam rumah tangga. Begitu juga apabila ada hal yang tidak baik maka akan berakibat buruk yang akan diterima.

\subsubsection{Makna Kewajiban Sebagai anak berbakti kepada orang tua}

Ajaran Bhtara Siwa dalam Lontar Andha Bhuwana terkait dengan pendidikan karakter yaitu seorang anak sebagai Bhatara Gana yang sangat hormat berbakti kepada orang tuanya yaitu Bhatara Siwa. Bhatara Gana disamping sebagai anak yang berbakti kepada orang tua juga sebagai anak yang pintar, mengusai segala macam ilmu pengetahuan, 
pengetahuan tersebut dimuat dalam Lontar Andha Bhuwana disebut wariga tenung. Wariga tenung tersebut mengetahui semua kejadian baik yang sekarang, terdahulu maupun yang akan datang. Wariga tenung ini dapat ditemukan dalam Lontar Andha Bhuwana yang dikuasai oleh Bhatara Gana. Bentuk kewajiban seorang anak yang berbakti kepada orang tua dapat dilihat pada kutipan berikut.

....,madêg ta sira Hyang Gurureka, raris ngandika ri puturan ira ring sira Hyang Bhatàra Gana :"Uduh anak ira bapa, Si Gana, iki rêngwakênajar hulun lawan kita anaku, agya ri lampah ira ibun ta Hyang Giriputri, duke lungha angulati we susu lêmbu, nda tan nana mànusa adrêwe lêmbu ring mànusapada. Matangyan bapa mawesa mànusa angangon lêmbu, têmun ira ibun ira ring Gunung Ekalaya. Sahika amajar babun ta lawan bapa, cittane babun ta manuku olih mas pirak rajata wintên manik, nghing hulun tan tinarima. Nghing hana pamidin ta aku lawan ibun ta, yen mahyun ibunya masanggama lawan mami, nghing hana pamidin ibun ta lawan bapan ta, kinon bapan ta pasanggama watek ing suku nira, sigra tang hulun pasanggama ring watêk sukunya, saksana mêtu sarwa kumatap-kumitip, kumangkana-kumingking, kumêdap-kumêdip. Mangkana kalinganya, apang anaku wruh.

Nihan rêngakêna ujar kami lawan anaku, tan len anaku ri mangke, anaku atanya-tanya lawan ibun ta, yan tuhu, yan tan tuhu ri ulah pasanggama lawan kami. Tan len anaku ngitungi juga ibun ta, caritakêna pawarah bapan ta, kewala carita ring tênung wariga têmên, mangka uncarakêna, aywa carita saking pawarah tang hulun. Mangka ling Bhatàra Gurureka”.

Terjemahan:
...., berdirilah beliau Bhatara Siwa, kemudian bersabda kepada putra beliau Bhatara Gana; "Ya anakku Bhatara Gana, hendaknya didengarkan sabda ayahndamu ini, ya anakku, jemputlah kedatangan ibumu Bhatari Giriputri, dating dari mencari air susu lembu, tetapi tidak ada manusia yang mempunyai lembu di dunia. Itulah sebabnya ayahndamu berwujud manusia mengembalakan lembu. Berjumpalah ayahndamu dengan ibumu di gunung Ekalaya. Pada waktu itu ada permintaan ibumu dengan ayahndamu, ibumu berkeinginan untuk membeli membeli atau menukar dengan emas, perak, permata, intan dan manikam, tetapi ayahmu menolaknya. Tetapi ada permintaan ayahmu terhadap ibumu, kalau ibumu mau bersenggama dengan $\mathrm{Ku}$, tetapi ada permintaan ibumu kepada ayah, ayahndamu disuruh bersenggama di bagian kakinya. Seketika itu ayahndamu bersenggama di bagian kaki ibumu. Pada waktu itu keluarlah beraneka macam kumatap-kumitip, kumangkangkumingking, kumedap-kumedip. Demikianlah perihalnya, supaya anakku mengetahuinya.

Sekarang dengarkanlah sabda ayah mu anakku, tiada lain sekarang anakku bertanya pada ibumu, apakah benar, atau berbohong tentang perbuatannya bersenggama dengan ayahmu. Tiada lain anakku sekarang menguji ibumu, ceritakanlah sabda ayahmu ini, tetapi ceritakan menurut kitab Wariga Tenung, itu hendaknya dibacakan, janganlah kau ceritakan bahwa hal itu dari sabda ayahmu. Demikian sabda Bhatara Siwa.

Berdasarkan kutipan di atas, wujud bhakti seorang anak ditunjukkan oleh Bhatara Gana ketika disuruh oleh Bhatara Siwa menanyakan perihal bagaimana cara Bhatari Giriputri mendapatkan air susu lembu. Bhatara Siwa menyampaikan bahwa lewat Wariga Tenung, semua perbuatan yang dilakukan oleh Bhatari Giriputri akan diketahui. Bhatara Gana menguji kejujuran 
perbuatan yang dilakukan oleh Bhatari Giriputri, hal inilah yang penting diajarkan dalam kehidupan. Seharusnya dalam mendapatkan sesuatu yang diinginkan harus dengan cara kerja keras dan benar. Bukan dengan cara menghalalkan segala cara untuk mendapatkan sesuatu yang diharapkan.

Berikutnya berkaitan dengan pertanyaan Bhatara Gana Kepada Ibunya yang menanyakan apakah air susu yang didapatkan ibunya dengan cara membeli, meminta atau menukar. Hal ini dilakukan untuk menguji tentang perjalanan Bhatari Giriputri sudah benar atau tidak. Hal ini dapat dilihat pada kutipan berikut.

...., Dadi umatur ta sira Hyang Bhatàra Gana: "Singgih pukhulun ta sira Hyang Bhatàra, ranak rahadyan sanghulun de Bhtàra misingih ling Hyang Bhatàra, umatur ring sira Hyang Bhtàrì Nareswari Tan dumade datêng ta sira Hyang Bhatàrì Giriputri anggawa we susu andaka winadahan kundi manik, sigra Hyang Bhatàra Gana umatur ring sira Hyang Bhatàrì Girìutri : "Udah ta sira Hyang Bhatàrì, kadyang apa pamargine sira Hyang Bhatàrì lungha angùlati mpêhan lêmbu ?" Kadyang apa olih tan olih?.

Dadi sumahur Bhatàrì Girìputri : "Eh ta kita anak ibu, ri mangko olih manira we susu lêmbu? Mangkana ling Hyang Bhatàrì. Manih umatur Hyang Bhatàra Gana: "Singgih ta sira Hyang Bhatàrì, ndi ta unggwane molih we susu andaka?" Age warah akêna ring hulun, Bhatàrì!. Manih sumahur Hyang Bhatàrì: "Eh anak ira, kaki hana ring gunung alas Ekalaya manira molih, mangka kaki". Manih umatur Bhatàra Gana: "Singgih ta sira Hyang Bhatàrì, kadyang apa sangkaning molih, sangkan atuku, sangkaning minta, sangkaning angurupi?" ya tika warahngkwa! Mangkana ling Bhatàra Gana.
Terjemahan:

...,Lalu berdatang sembahlah Bhatara Gana: ya hampun tuanku Bhatara, putramu menuruti seperti sabda akan bertanya kepada Bhatari Giriputri. Tiada lama datanglah beliau Bhatari Giriputri membawa air susu lembu ditempatkan pada kundi manik. Segeralah Bhatara Gana bertanya kepada Bhatari Giriputri. Ya ampun ibundaku Bhatari, bagaimanakah perjalanan Bhatari pergi mencari air susu lembu, bagaimana dapat atau tidak?

Bersabdalah Bhatari Giriputri, duhai putraku ibumu berhasil mencari air susu lembu. Demikianlah sabda Bhatari Giriputri. Lagi bertanya Bhatara Gana; ya hampun bhatari, dimana tempatnya ibunda mendapatkan air susu lembu itu? Beritahukannlah hamba ya Bhatari, kemudian dijawab oleh Bhatari Giriputri, Ya Putraku di hutan Gunung Ekalaya ibumu mendapatkannya, demikian anakku. Lagi Bhatara Gana bertanya, Ya hampun ibunda Bhatari, bagaimmana caranya ibunda mendapatkannya? Apakah dengan jalan membeli, dengan meminta, atau dengan jalan menukar? Itu hendaknya ibu menjelaskannya. Demikian pertanyaan Bhatara Gana.

Berdasarkan kutipan di atas Bhatara Gana sebagai simbul anak dan siswa religius, jujur, pintar, disiplin, berkarakter baik yang patut diteladani oleh semua orang terutama dalam hubungannya dengan pendidikan karakter. Sebagai bentuk rasa bhakti anak kepada orang tua Bhatara Gana melkukan perintas dan tugas yang diberikan ayahnya untuk mencari informasi kebenaran ibunya yang dalam memperoleh air susu lembu dengan cara yang tidak benar. Selain itu, bhatara Gana mengutuk ibunya sebagai bentuk karma dari perbuatan yang tidak baik. Oleh karena itulah kepada siapa pun harus selalu jujur dan berbhakti kepada orang tua. 


\subsubsection{Makna Ajaran Siwa Sebagai Bentuk Mensyukuri Kehidupan}

Dalam cerita Adha Bhuwana adanya tingkah laku dan laksana suci yang bertujuan untuk membebaskan diri dari kekotoran harus sesuai dengan ajaran Tri Kaya Parisudha. Orang yang mendapatkan sorga adalah mereka yang telah melaksanakan ajaran dharma. Orang-orang poraka memiliki sifat yang jelek atau buruk akan mendapatkan siksaan dan disiksa di kawah Yamadiloka. Hal inilah yang seharusnya dapat dipahami bahwa ajaran-ajaran yang sesuai dengan Tri Kaya Parisudha akan menuntun umat manusia untuk dapat mensyukuri kehidupan di dunia ini.

\subsubsection{Makna Ajaran Siwa Sebagai Bentuk Penyucian diri (Pangruatan) dan Harmonisasi Alam}

Makna pangruatan sebagai

penghilang sifat-sifat buruk pada diri manusia mempunyai dua makna yaitu penyucian lahiriah dan batiniah. Upacara yang melambangkan penyucian lahiriah dilengkapi dengan upacara penyucian batiniah dengan menggunakan upakara atau banten Prayascitta (Wiana, 2002: 167). Pelaksanaan pangruatan sebagai bentuk upacara penyucian merupakan bentuk penghilangan sifat-sifat buruk pada diri manusia. Pelaksaan pangruatan sebagai penghilang sifat-sifat buruk pada diri manusia

Selain itu Kekotoran alam dalam hal ini berkaitan dengan adanya wabah penyakit yang terjadi di bumi. Alam yang kotor akibat wabah penyakit, apabila tidak dinetralisir akan berdampak kepada semua makhluk yang ada di dalamnya. Pelaksanaan upacara penyucian alam sangat penting dilakukan untuk mengharmoniskan kembali alam beserta segala isinya, termasuk kahyangan sebagai alam para dewa.

Keberadaan alam yang kacau dan terkena wabah penyakit perlu diupacarai supaya kembali menjadi harmonis. Upacara yang dilakukan untuk mengharmoniskan kembali alam ini adalah dengan cara macaru. Caru untuk mengharmoniskan bumi atau alam sekitar dengan lingkungannya disebut dengan "Bhumi Suddha". Caru Bhumi Suddha dimaksudkan untuk membersihkan bumi dan lingkungannya dari pengaruh Bhuta Kala, dengan cara memberikan korban dan memindahkannya ke tempatnya masingmasing yakni di hutan dan lain-lainnya (Wikarman, 1998: 15).

\section{KESIMPULAN}

Ajaran Bhatara Siwa yang terdapat dalam lontar Andha Bhuwana berkaitan dengan Pendidikan Karater adalah: karakter jujur, religius, tanggung jawab, bersahabat/komunikatif, peduli sosial, menghargai prestasi, dan kerja keras. Semua hal tersebut memberikan ajaran kepada setiap orang terutama dalam hal pendidikan supaya dapat mendidik anak menjadi memiliki kualitas dan kompetensi yang berani bersaing dalam segala bidang. Makna ajaran Bhatara Siwa dalam lontar Andha Bhuwana yaitu: 1). Sebagai bentuk keharmonisan dalam perkawinan/berumah tangga, 2). Kewajiban sebagai anak berbhakti kepada orang tua, 3). Mensyukuri kehidupan, 4). Penyucian diri (pangruatan) dan harmonisasi alam.

\section{DAFTAR PUSTAKA}

Adi Armini. 2015. Peranan Anak Menurut Susastra Hindu (Mewujudkan Jati Diri Anak Hindu Sadhu-Madhuwa) Guna Widya Jurnal Pendidikan Hindu. 
GUNA WIDYA : JURNAL PENDIDIKAN HINDU JURUSAN PENDIDIKAN AGAMA FAKULTAS DHARMA ACARYA

UNIVERSITAS HINDU NEGERI I GUSTI BAGUS SUGRIWA DENPASAR
VOLUME 8 NOMOR 1 MARET 2021

ISSN : 2355-5696 (CETAK)

ISSN : 2655-0156 (ONLINE)

http://ejournal.ihdn.ac.id/index.php/GW
Jurnal Volume 2, No 1. Fakultas Dharma Acarya IHDN Denpasar

Samani. 2011. Konsep Dan Model Pendidikan

Karakter. Bandung : PT. Remaja

Rosdakarya

Sariani Binawati. 2015. Kajian Cerita Rakyat

Bali Yang Mengandung Nilai Kearifan

Lokal Sebagai Model Pendidikan

Karakter. Kearifan Lokal Indonesia

Untuk Pembangunan Karakter

Universal. Prosiding Seminar

Nasional Fakultas Dharma Acarya

IHDN Denpasar

Sugiyono.2006. Metode Penelitian

Pendidikan (Pendekatan Kuantitatif,

Kualitatif dan R\&D). Bandung:

Alfabeta.

Suharsimi, A. 2006. Prosedur Penelitian Suatu Pendekatan Praktis. Jakarta : Rineka Cipta.

Sutryanti. 2013. Perkembangan Dan Karakter Anak Perspektif Ilmu Dan Agama Guna Widya Jurnal Ilmiah Ilmu Pendidikan Agama. Jurnal Volume 5, No 1. Jurusan Pendidikan Agama Fakultas Dharma Acarya IHDN Denpasar

Undang-undang RI No 20 Tahun 2003. Sistem Pendidikan Nasional

Wiana, I Ketut. 2002. Makna Upacara Yadnya dalam Agama Hindu. Surabaya: Paramita.

Wikarman, I Nyoman Singgin. 1998. Bayuh Oton Ruwatan Menurut Hindu. Surabaya: Paramita.

Yendra. 2009. Kanda Empat Dewa Manusia Setengah Dewa Sakti

Manderaguna. Paramita : Surabaya
Zoetmulder, P.J. S.O. Robson. 2011. Kamus Jawa Kuna- Indonesia. Cetakan keenam (Diterjemahkan Oleh Darusuprapta dan Sumarti Suprayitna). Jakarta: PT. Gramedia Pustaka Utama. 